\title{
SEASONS IN STUTTGART: DEVELOPING A GOOGLE EARTH ENGINE TOOL FOR HEAT ISLAND MAPPING
}

\author{
R. Zafrir ${ }^{1}$, S. Ojeda ${ }^{1}$, H. Singh ${ }^{1}$, M. Hahn ${ }^{1}$ \\ ${ }^{1}$ Dept. of Geomatics, Computer Science and Mathematics, Hochschule für Technik Stuttgart, 70174 Stuttgart, Germany - \\ (82zara1mpg, 82ojjo1mpg, 82siha1mpg, michael.hahn)@hft-stuttgart.de
}

KEYWORDS: Remote Sensing, Land Surface Temperature, Landsat, Urban Heat Island, Google Earth Engine, Python.

\begin{abstract}
:
This study generates a process in GEE (Google Earth Engine) for SUHI (Surface Urban Heat islands) identification derived from TIRS (Thermal Infrared Sensor) and OLI (Operational Land Imager) sensors of Landsat 8 imagery in the area of Stuttgart, Germany. By comparing the temperature images in winter and summer seasons through a regression model, a relation between the Surface Cover (SC), the Terrain Shape (DEM) and the LST (Land Surface Temperature) is established. A Python code is developed for modelling the data and displaying the results linked to GEE. Three different models are used to establish the relationship between different variables (Temperature, Height, Wind etc.). Accuracy/goodness of fit of these models are measured using R-squared and standard error. Results shows that polynomial regression of 3rd order degree fits best to the dataset used in this study. Moreover, it is found that temperature values are not perfect for this study, as Landsat 8 have been acquired at 10'o clock in the morning (local time), whereas night time acquisition (which was not available for Stuttgart, Germany) would be best suited for the study. The results indicate that urban areas and meadow (open areas without vegetation) get the bigger values of temperature. Terrain Shape with respect to height indicates that the bigger the height, the lower the temperature in most of the regions. This project provides insight into the development of applications using a web-based platform and leads to a fast and accurate result for identifying the SUHI effect. It can contribute to the necessity of planning more vegetation areas in order to reduce hot temperature values in Stuttgart.
\end{abstract}

\section{INTRODUCTION}

The global warming during the last years, the increasing temperatures, the migration of people from rural to urban areas and the extensive urban expansion and population growth have triggered a series of environmental problems. Those are resources crises (Liu et al., 013), local climate change (Parmesan and Yohe, 2003), air pollution (Yuan et al., 2017), traffic congestions (Evans ad Carrère, 1991) among others. As temperatures rise, so do the highest values in urban areas. Using remote sensing imagery, those values can be identified and measured in an accurate way using the Google Earth Engine. This is done with a bit of code and without downloading big amounts of data because everything is stored in the cloud. The SUHI should be considered by the local authorities because its consequences can lead to community stress due to the problems mentioned above, mainly during the daytime (Zhou et al., 2011).

The project identifies the SUHI effect using a Web-based platform, the Google Earth Engine. Open sources and free Landsat 8 images are used, and a method is developed to quickly generate accurate results of SUHI.

\section{STUDY AREA}

Stuttgart is a city situated just at the hearth of Baden Württemberg. There are over 620 thousand inhabitants in Stuttgart City and around 4 million in the Stuttgart Region (Eurostat, 2018) with a land extension of around $3654 \mathrm{~km}^{2}$.

The need of land for urban expansion is putting some pressure onto the city and surrounding forest areas. Figure 1 shows the shape of the Stuttgart Administrative District.

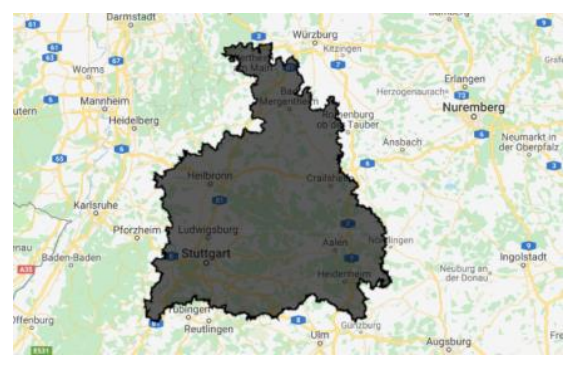

Figure 1: Stuttgart Administrative District. 


\section{DATA}

To differentiate the area of study, a shape file of the boundary of Stuttgart Region is loaded into the GEE Interface. This boundary helps to limit the area of study and to clip the input data used in the project. A dataset used is Landsat 8 imagery with multispectral and thermal images, a Digital Elevation Model (DEM) from the PALSAR sensor, which are open data and available through Google Earth Engine dataset catalogue. Further a raster model for the wind in the Stuttgart area is uploaded to the GEE interface.

For the Stuttgart area the analysis is divided into two seasons: Winter (January) and Summer (August) as explained in Section 5.1. Only images with cloud coverage less than $10 \%$ are selected. Due to the climate conditions in winter a suitable image was difficult to find for the winter season.

\subsection{Landsat 8 - OLI and TIRS}

The Operational Land Imager (OLI) and Thermal Infrared Sensor (TIRS) are instruments for data acquisition onboard the Landsat 8 satellite (USGS, 2019) and both are used in this project. To generate the Land Surface Temperature and the Land Cover the following Landsat images were used: LC08_194026_20160114 for the Winter season, LC08_194026_20150604 for the Spring season, for the Summer season LC08_194026 20130801 and for the Autumn season LC08_194026_20171015. Each image is addressed by the image ID. The first two values (LC) means the data product include data combined (both the OLI and TIRS sensor), the values LO or LT means that the data product contains only OLI or TIRS data respectively. For the two images the same path and row were used according the Worldwide Reference System (WRS) for Landsat data, it can be identified in the ID image after the LC value (Path 194, Row 026). The WRS is a global notation to identify satellite imagery over any portion of the world, in this case covering the whole extension of Stuttgart Administrative District, specifying a nominal scene centre designated by the values mentioned above 194 and 26 for both images (NASA, 2019). For the thermal data used in the computation of LST an image from Landsat 8 Thermal Infrared Sensor (TIRS) Tier 1 dataset is obtained.

These datasets contain the corrected surface reflectance from the Landsat $8 \mathrm{OLI} / \mathrm{TIRS}$ sensors with 5 visible and near-infrared (VNIR) bands and 2 short-wave infrared (SWIR) bands processed to orthorectified surface reflectance, and two thermal infrared (TIR) bands processed to orthorectified brightness temperature. These bands were originally collected with a resolution of $100 \mathrm{~m}$ and have been resampled using cubic convolution to $30 \mathrm{~m}$ (USGS, 2017).

\subsection{DEM Alos Palsar}

For the Terrain Shape, a Digital Elevation Model was obtained using the Google Earth Engine Interface from ALOS satellite who collected radar images with $50 \times 70 \mathrm{~km}$ scenes around the world each 45 days approximately through its PALSAR sensor (Phased Array Type L-band Synthetic Aperture Radar). A scene of 30 metres resolution was used for this project using a script in Google Earth Engine.

\subsection{Wind}

A raster with the values of the wind for the area of interest is downloaded from the web page Global Wind Atlas and was limited to the State of Baden Württemberg and the city of Stuttgart. The lower value is around $4 \mathrm{~m} / \mathrm{s}$ and the maximum value is $7 \mathrm{~m} / \mathrm{s}$ (see figure 12). Other historical data could not be obtained because Google has closed their Weather and Cloud solutions since $4^{\text {th }}$ of June 2015 and recommended to use OpenWeatherMap with the google Maps JavaScript API (Open Weather Map, 2019) or the PyOWM client Python library to access and download the weather data, but the historical is not for free.

\section{METHODOLOGY}

\subsection{Land Surface Temperature LST}

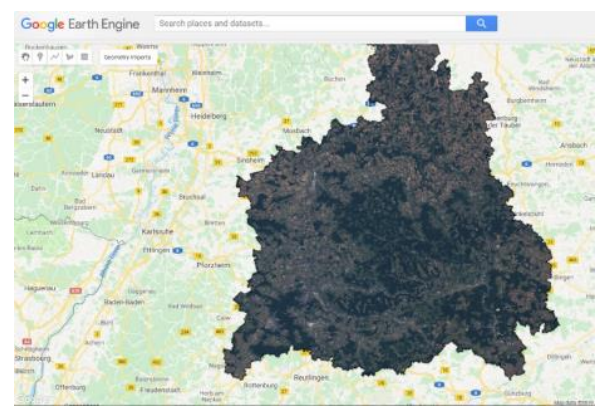

Figure 2: Landsat 8 image of Stuttgart

The data retrieved from Band 10 stores surface temperature in Kelvin. Band 10 covers a spectral width of $10.60-11.19 \mu \mathrm{m}$. With a portion of code in Google Earth Engine (subtracting 273.15) the LST value is converted into Celsius.

\subsection{Terrain Shape}

The terrain shape was obtained from the Digital Elevation Model (DEM Alos Palsar), this input data is used in order to define if there is a dependency between the Land Surface Temperature LST obtained in the previous step and the height in every value of pixel in the DEM.

\subsection{Surface Classification}

A supervised classification was developed in the GEE interface using the Landsat 8 image from Stuttgart and collected training data in order to store the values in known class labels. For this project, four classes were used to classify the area of study (Urban - Vegetation - Water - Meadow). For classification the classifier "ee.Classifier.cart" was employed.

\subsection{Regression Model}

Using as inputs the DEM, Wind and the Surface Classification, three kinds of regression models were analysed to obtain a better understanding between the correlation of the input data and the result of the Land Surface Temperature in the Winter and Summer seasons in Stuttgart (see Figure 8 and 9). 
A Linear Regression (1), Ordinary Least Squares Regression (2) and a Polynomial Regression (3) are implemented to obtain both, the graphic result ( 2 dimensions figure where the $y$-axis the dependent variable is the temperature in Celsius and the $\mathrm{x}$-axis the input data used to explain the LST) and the numerical result (R-squared and Standard Deviation Error values).

$$
\begin{aligned}
& y=m x+b \\
& y=m_{1} x_{1}+m_{2} x_{2}+b \\
& y=a_{0} x^{3}+a_{1} x^{2}+a_{2} x+a_{3}
\end{aligned}
$$

\subsection{Work chart}

The overall processing scheme is visualised in figure 3 .

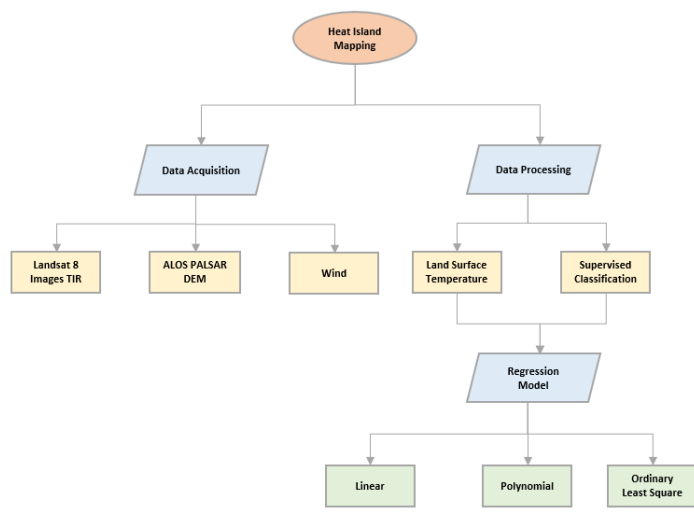

Figure 3: Surface Urban Heat Island Work chart

\section{RESULTS}

\subsection{Land Surface Temperature LST}

In order to obtain a mean value of temperature in the area of study, the mean is calculated to four Landsat 8 images which overlap in the black line (line used to generate a profile of the temperature per season in GEE, of the year 2014. The two figures (5 and 6) show the mean temperature profile per season along the black line of Figure 5. The profile shows an expected big difference between the summer and winter season, for that reason, only the images of those seasons were used in the regression model.

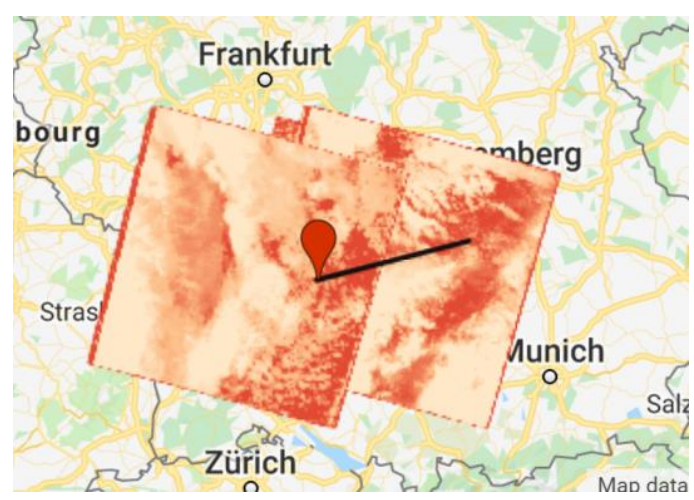

Figure 4: Stuttgart mean temperature per Season - Images

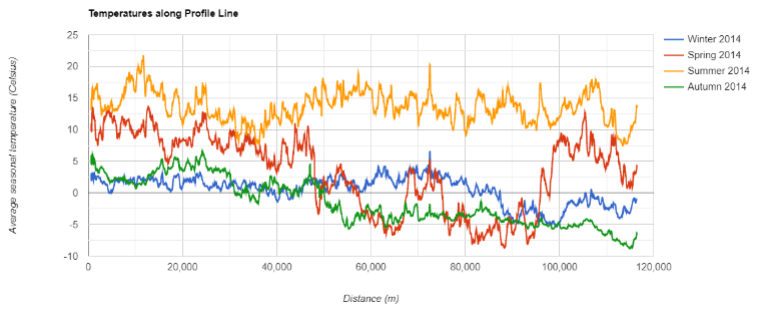

Figure 5: Stuttgart mean temperature per Season - Profile

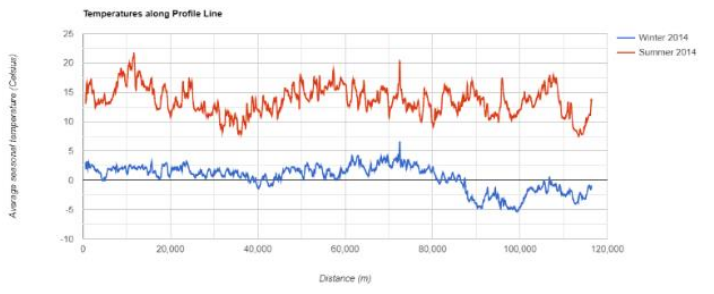

Figure 6: Profile for Winter and Summer

The final result is a raster image for each season with the pixel as temperature value in Celsius degrees, with a 30-meter resolution for the Stuttgart area. The dark red colour correspond to higher temperature values and lighter colour means lower temperature values.

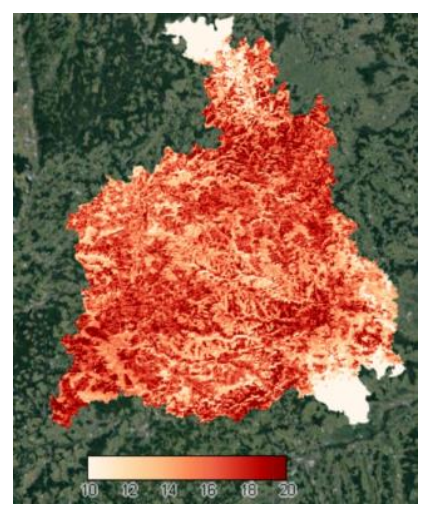

Figure 7: LST Stuttgart - Autumn. 


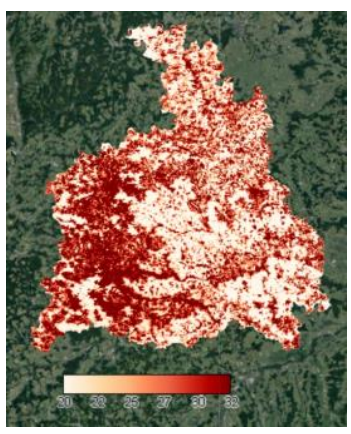

Figure 8: LST Stuttgart - Spring.

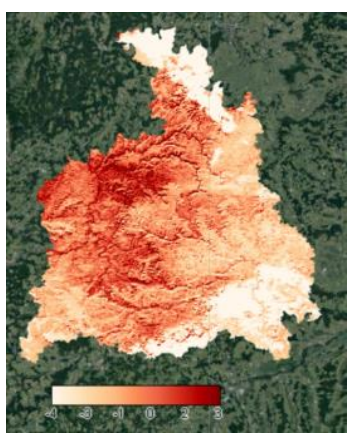

Figure 9: LST Stuttgart - Winter.

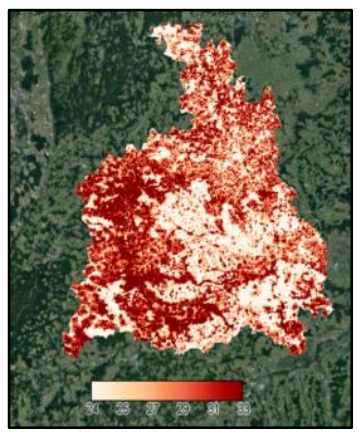

Figure 10: LST Stuttgart - Summer.

\subsection{Wind}

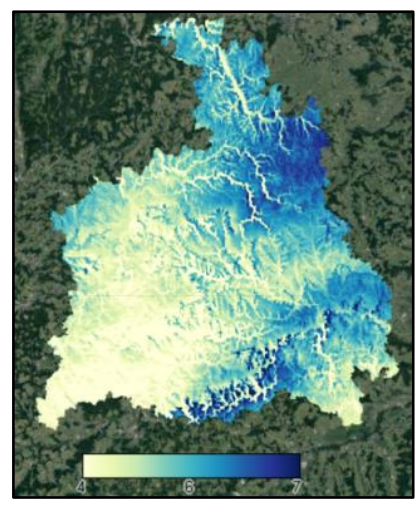

Figure 11: Wind raster

\subsection{Surface Classification}

As outlined in the methodology, a supervised classification in GEE was developed using a Landsat image and four training classes.

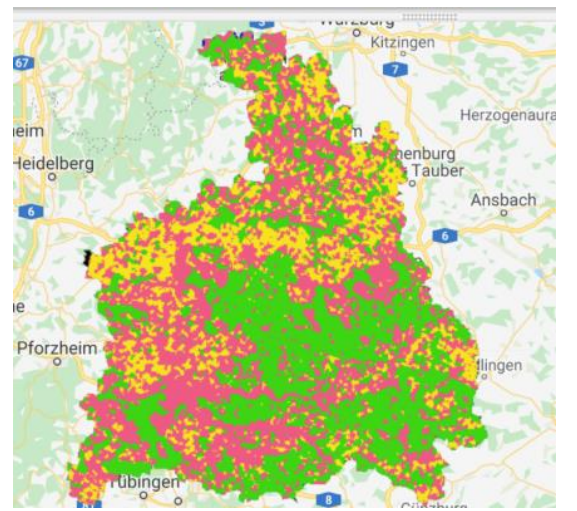

Figure 12: Stuttgart Surface Classification in GEE

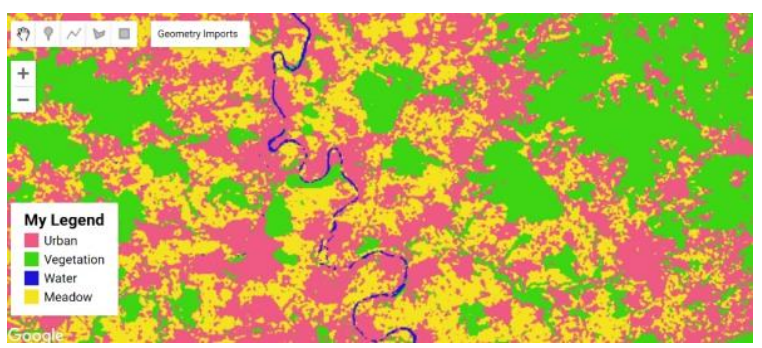

Figure 13: Zoom to Figure 12 (the Neckar river can be seen in the centre of the image)

\subsection{Terrain Shape}

The figure 14 shows the 30-meter resolution height for the Greater Stuttgart area. The highest values can be seen in the south-east part, this sector has values of around 800 meters between the cities of Aalen, Göppingen, Schwäbisch Gmünd and Heidenheim an der Brenz.

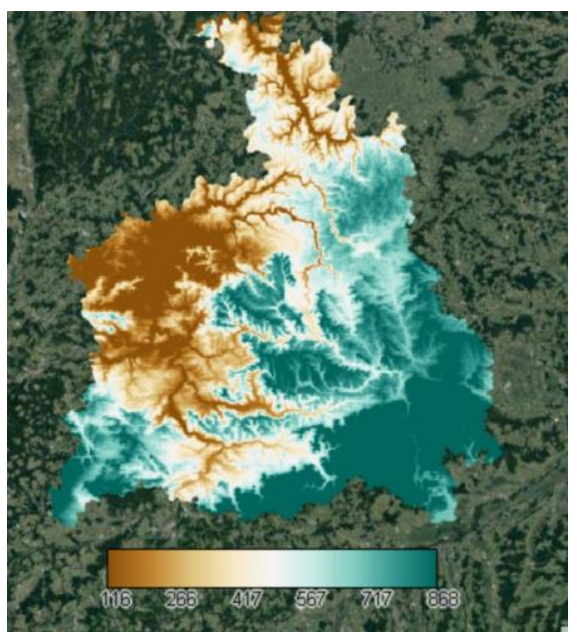

Figure 14: DEM Alos Palsar 30 m resolution 


\subsection{Linear Regression}

The regression model was used to approximate the dependency relation between the Land Surface Temperature in the Stuttgart area and the independent variables used such the wind, elevation and the surface classification. In the case of the linear regression (see figure 16) the orange line represents the relation between the LST and the elevation for every season (autumn, spring, winter and summer).
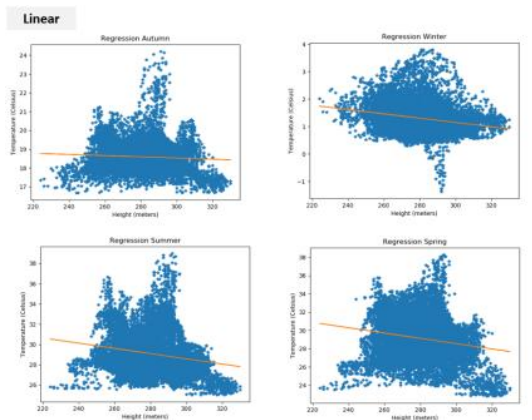

Figure 15: Linear Regression Model LST in 4 seasons (Temperature vs. Height)

In addition to the linear regression, another one was developed by taking into account the four classes of the surface classification (meadow, urban, vegetation and water) for the summer (figure 16) and winter season (figure 17), just like the first linear regression, the orange line represents the relation between the LST and the elevation.
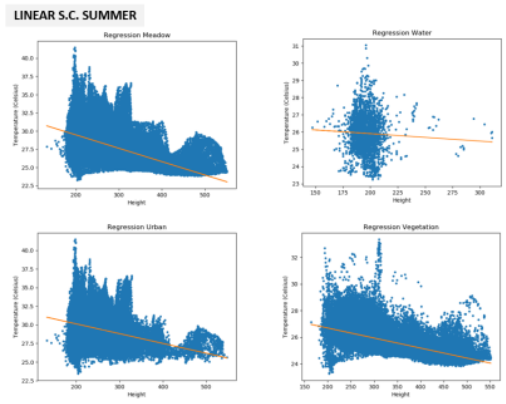

Figure 16: Linear Regression Model in Summer (Temperature - Land Cover)
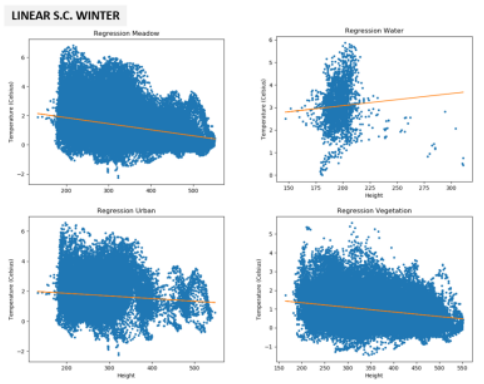

Figure 17: Linear Regression Model in Winter (Temperature - Land Cover)

\subsection{Polynomial Regression}

The third order polynomial regression model was used in order to improve the previous linear regression and try to understand better the behaviour of the Land Surface Temperature in the Stuttgart area and the independent variables. Just like the linear regression, the orange line represents the relation between the LST and the elevation for every season (autumn, spring, winter and summer).
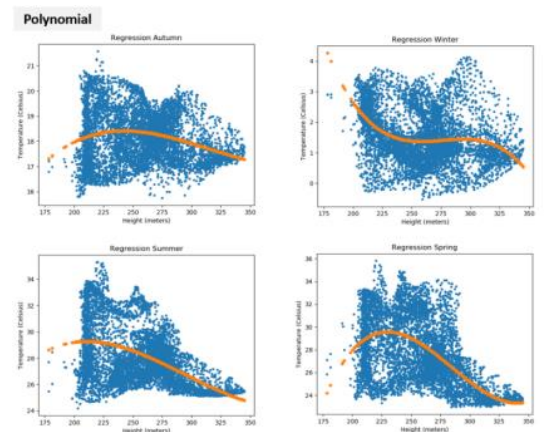

Figure 18: Polynomial Regression Model LST in 4 seasons (Temperature vs. Height)
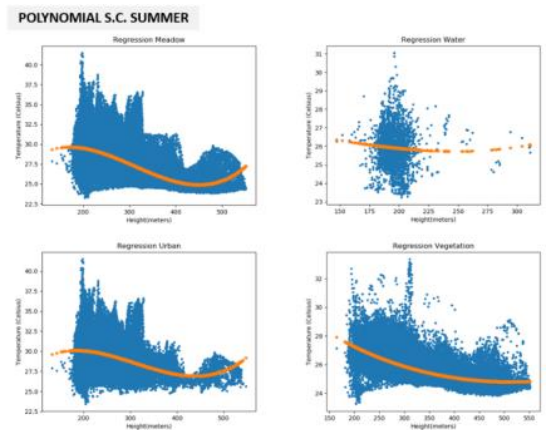

Figure 19: Polynomial Regression Model in Summer (Temperature - Land Cover)

For the third order polynomial regression, the four classes of the surface classification (meadow, urban, vegetation and water) for the summer (figure 19) and winter season (figure 20) were taken into account.
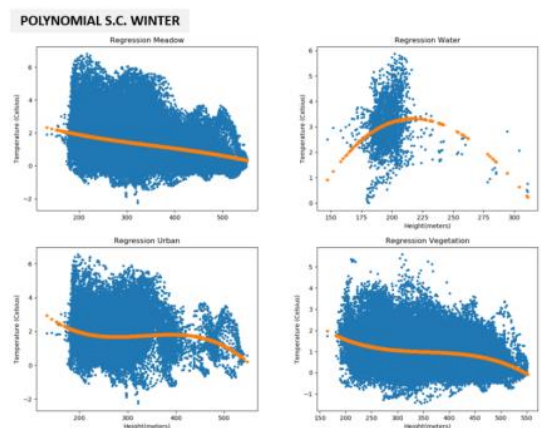

Figure 20: Polynomial Regression Model in Winter (Temperature - Land Cover) 


\subsection{Ordinary Least Squares Regression OLS}

An Ordinary Least Squares regression was the last model used in the project, in this case a multiple linear regression is used with the independent variable of wind in addition to the variables of height and surface classification. The Ordinary Least Squares Regression was developed using the DEM variable and the Wind variable and both variables for winter and summer seasons (see figures 21 to 26 ).
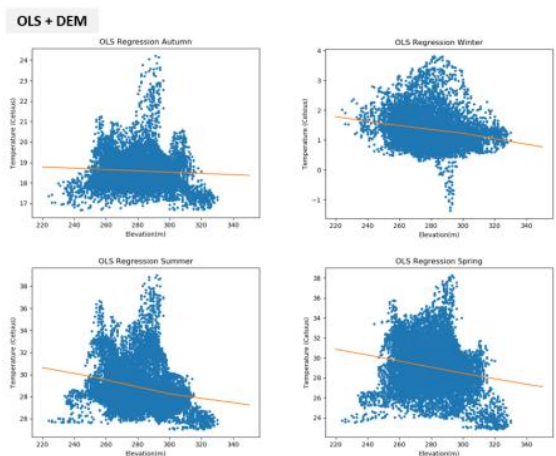

Figure 21: OLS Regression Model LST in 4 seasons (Temperature - Land Cover - DEM)
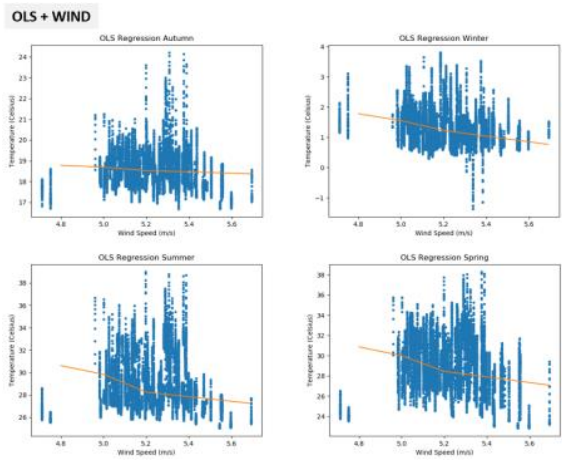

Figure 22: OLS Regression Model LST in 4 seasons (Temperature - Land Cover - Wind)
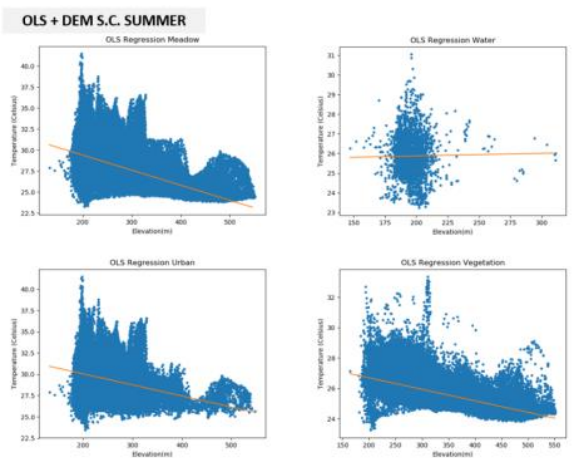

Figure 23: OLS Regression Model in Summer (Temperature Land Cover - DEM)
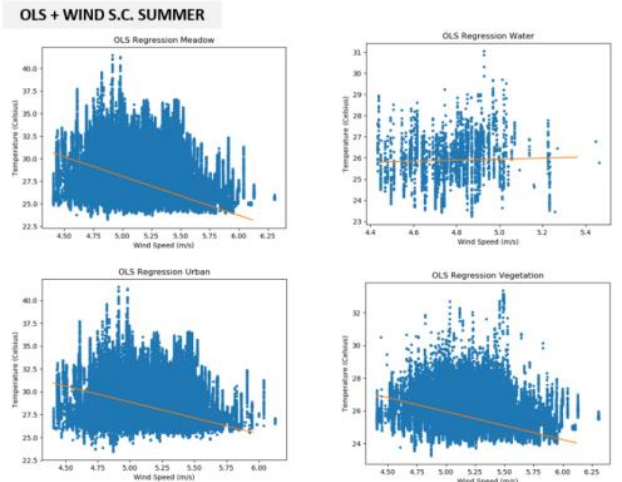

Figure 24: OLS Regression Model in Summer (Temperature Land Cover - Wind)
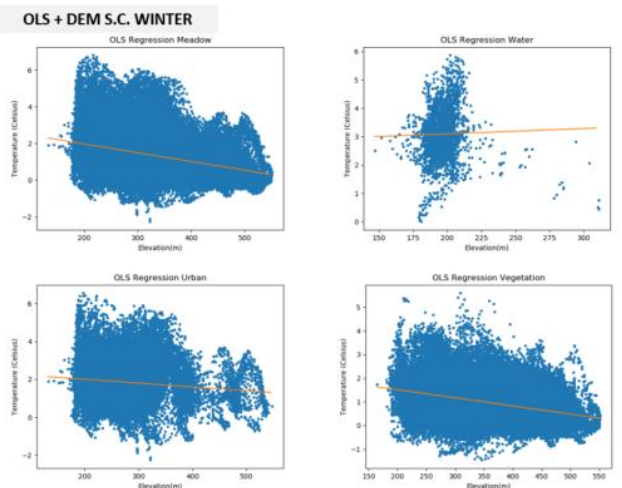

Figure 25: OLS Regression Model in Winter (Temperature - Land Cover - DEM)
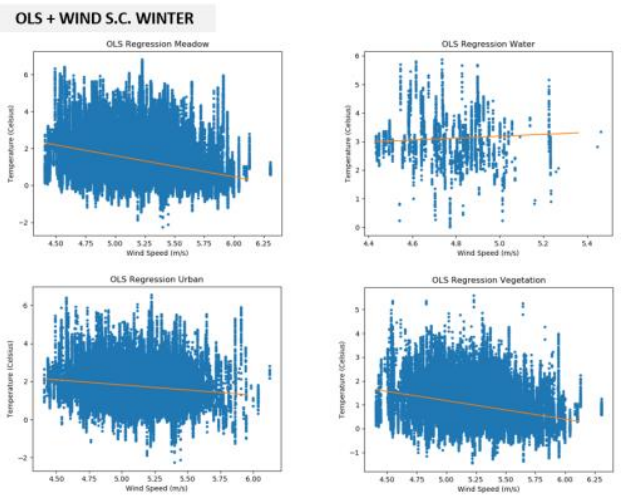

Figure 26: OLS Regression Model in Winter (Temperature - Land Cover - Wind)

As a summary for the regression models, the next three tables (Table 1 to 3) show the R-Squared and the Standard Error of every developed regression for each regression model (Linear Polynomial - Ordinary Least Square) 


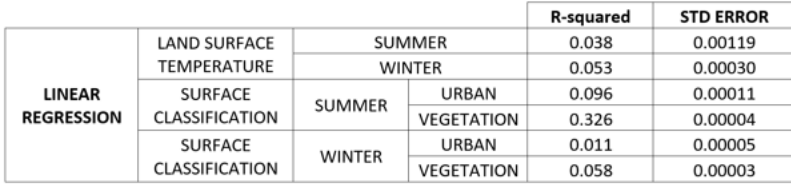

Table 1: Linear Regression

\begin{tabular}{|c|c|c|c|c|c|}
\hline & & & & R-squared & STD ERROR \\
\hline \multirow{6}{*}{$\begin{array}{l}\text { POLYNOMIAL } \\
\text { REGRESSION } \\
\text { GRADE } 3\end{array}$} & \multirow{2}{*}{$\begin{array}{l}\text { LAND SURFACE } \\
\text { TEMPERATURE }\end{array}$} & \multicolumn{2}{|c|}{ SUMMER } & 0.249 & 0.02100 \\
\hline & & \multicolumn{2}{|c|}{ WINTER } & 0.130 & 0.03200 \\
\hline & \multirow{2}{*}{$\begin{array}{c}\text { SURFACE } \\
\text { CLASSIFICATION }\end{array}$} & \multirow{2}{*}{ SUMMER } & URBAN & 0.103 & 0.009 \\
\hline & & & VEGETATION & 0.358 & 0.005 \\
\hline & \multirow{2}{*}{$\begin{array}{c}\text { SURFACE } \\
\text { CLASSIFICATION }\end{array}$} & \multirow{2}{*}{ WINTER } & URBAN & 0.022 & 0.019 \\
\hline & & & VEGETATION & 0.065 & 0.013 \\
\hline
\end{tabular}

Table 2: Polynomial Regression

\begin{tabular}{|c|c|c|c|c|c|}
\hline & & & & R-squared & STD ERROR \\
\hline \multirow{6}{*}{$\begin{array}{c}\text { OLS } \\
\text { REGRESSION }\end{array}$} & \multirow{2}{*}{$\begin{array}{l}\text { LAND SURFACE } \\
\text { TEMPERATURE }\end{array}$} & \multirow{2}{*}{$\begin{array}{l}\text { DEM + } \\
\text { WIND }\end{array}$} & SUMMER & 0.0476 & 2.106 \\
\hline & & & WINTER & 0.0612 & 0.538 \\
\hline & \multirow{4}{*}{$\begin{array}{c}\text { SURFACE } \\
\text { CLASSIFICATION }\end{array}$} & \multirow{2}{*}{ SUMMER } & URBAN & 0.0961 & 1.912 \\
\hline & & & VEGETATION & 0.3264 & 0.757 \\
\hline & & \multirow{2}{*}{ WINTER } & URBAN & 0.0273 & 0.775 \\
\hline & & & VEGETATION & 0.0160 & 0.872 \\
\hline
\end{tabular}

Table 3: Ordinary Least Square Regression

All these results indicate that surface cover as urban and meadow which are open areas without vegetation get the bigger values of temperature and the terrain shape indicates that the bigger the height, the lower the temperature,

This generalized conclusion is not totally true as can see in figures 28 and 29 where the Land Surface Temperature of the summer season are not the lowest value in the area of the higher values of the DEM.
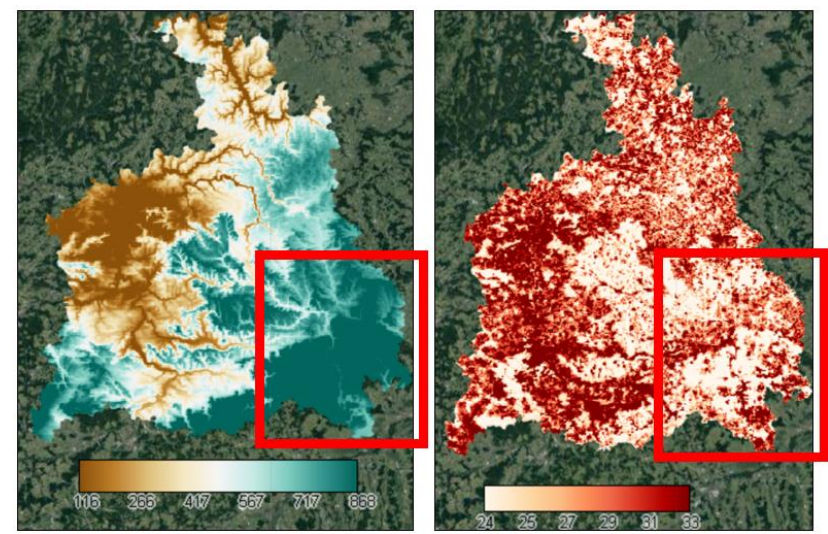

Figure 27: Comparison between the Temperature and DEM values

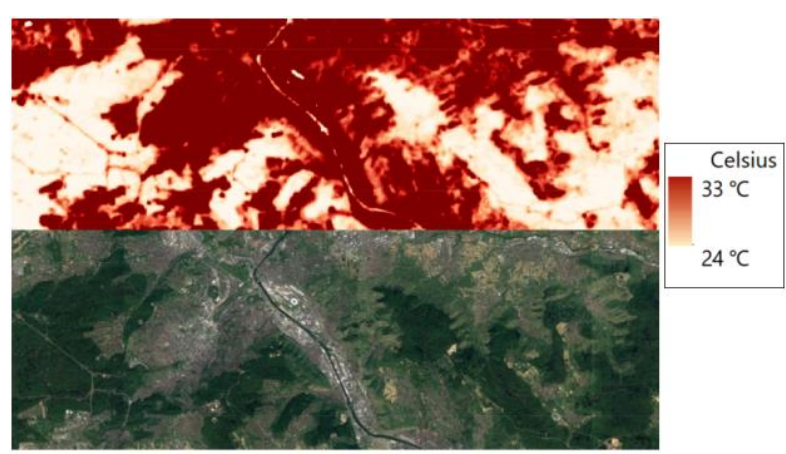

Figure 28: Land Surface Temperature in summer season vs. Landsat 8 image

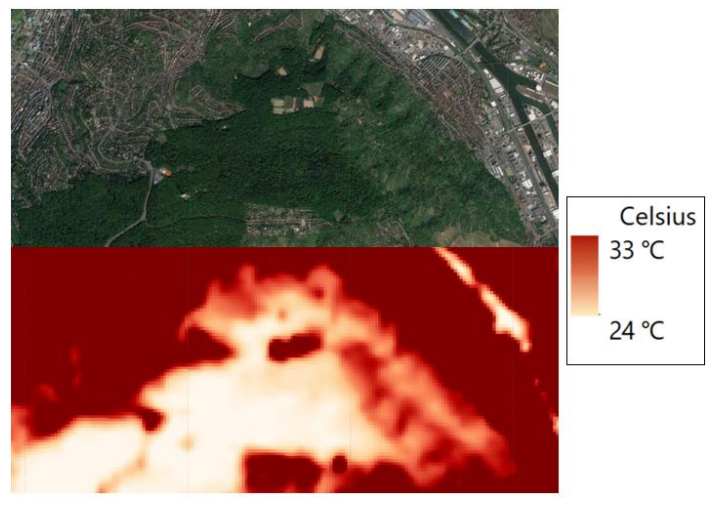

Figure 29: Land Surface Temperature in summer season vs. Landsat 8 image (zoomed)

As can be seen in the figure 27 there is a differentiation between the high and low values in the Land Surface Temperature corresponding first to the urban and open areas and second to the vegetation respectively. So, as shown in the figure above (even with a 30-meter resolution image) the final mapping of the SUHI is very reliable. To conclude, we can infer that urban areas have the highest temperatures no matter the season, and the vegetation areas even inside the urban boundaries have less temperature values. It is important to start greening our cities to improve the well-being and with strategic placement of trees in urban areas, the air can be cooled by between $2{ }^{\circ} \mathrm{C}$ and $8{ }^{\circ} \mathrm{C}$ (FAO, 2019).

Proposed methodology establishes a relationship between various input variables and hence enables the scientific community to analyse and study influences on Surface Urban Heat Island. The statistical results of various regression models are of limited quality, because the temperature data at 10 'o clock is highly scattered. It can be expected that night time TIRSLandsat 8 dataset will improve the results significantly. However, aim of this study was to explore a method/tool in GEE, which can be used to study Heat Islands. 


\section{CONCLUSIONS}

Google Earth Engine is a powerful application in order to use big amount of data because it does not require local storage if images, but allows analysing the satellite images in the cloud-based processing. It enabled us to process a large amount of satellite and vector data in a very simple way. No installation nor data download is required but only a registration to the platform.

Standard Error in the regression models shows deviation of data points around the regression line, so lower values of Standard Error correspond to a better model fit. In the same way, the RSquared value is a coefficient of determination; this coefficient is the total variation in the dependent variable (Land Surface Temperature) that is explained by variation in the independent variable (DEM, Wind, Surface Classification). Higher values of R-Squared means higher relational dependency of both variables. Using the R-Squared and the Standard Error result values, they prove that Polynomial Regression model gives the best fit for modelling these dependencies.

The use of GEE is very helpful, accurate and useful for mapping the urban heat island in the area of interest. By using the thermal band of Landsat 8 through the GEE interface, there is no need to generate any additional process in order to obtain the temperature.

The use of programming scripts (JavaScript or Python) are required in order to take full advantages of the platform capabilities but a strong programming background is no needed because there is plenty information in the Google Earth Engine web page for developers where some portions of code are already developed.

\section{ACKNOWLEDGEMENT}

This publication was produced in the project „Neue Möglichkeiten der Datenerhebung, -analyse und Auswirkungsabschätzung im Wasser-Energie Nexus - NeMDa“, which is part of the Baden-Württemberg-STIPENDIUM for University Students - BWS plus, a programme of the BadenWürttemberg Stiftung. The authors would like to thank the Baden-Württemberg Stiftung for its support.

\section{REFERENCES}

N. Gorelick, M. Hancher, M. Dixon, S. Ilyushchenko, D. Thau and R. Moore. Google Earth Engine: Planetary- scale geospatial analysis for everyone. 2017. Remote Sensing of Environment.

The European Space Agency, Sentinel-2 User Hand- book, ESA Standard Document, ESA Sentinel Online, 2015, Issue 1 Rev 2.

U.S. Geological Survey, Product Guide - Landsat 8 Sur- face Reflectance Code (Lasrc), LaSRC Product Guide, 2018, Version 4.3.

Pettorelli N., The Normalized Difference Vegetation Index. 2013. First Edition (United Kingdom: Oxford University Press) p 193.

F. Kogan, M. Vargas, H. Ding and W. Guo, VHP Al- gorithm Theoretical Basis Document, NOAA NESDIS Center for
Satellite Applications and Research, 2011, Version 1.0.

J. Weier and D. Herring, Measuring Vegetation (NDVI \& EVI). NASA Earth observatory, 2000, https://earthobservatory.nasa.gov/Features/MeasuringVegetatio $\mathrm{n} /$

Viewed June 2019.

Google Inc., Google Earth Engine API, https://developers.google.com/earth-engine/ Viewed June 2019.

Google Inc. Google Earth Engine, https://earthengine.google.com/faq/ V V V V 2019.

Open Weather Map, Google Maps JavaScript API, https://openweathermap.org/examples/ Viewed May 2019.

Github, Python wrapper library for Open Weather Map web API, https://github.com/csparpa/pyowm/ Viewed May 2019.

Things Are Heating Up: The Urban Heat Island Effect \& Your Roof, http://homeebuzz.blogspot.com/2015/11/things-areheating-up-urban-heat-island.html/ Viewed June 2019

Benefits of urban Tress, FAO (Food and Agriculture Organization of the United Nations), http://bit.ly/2SVdlN1/ Viewed June 2019.

Statistisches April 2019.

Viewed

Eurostat, your key to European Statistics, https://ec.europa.eu/eurostat/en/web/population-demographymigration-projections/statistics-illustrated/ Viewed June 2019.

USGS EROS Archive (U.S. Geological Survey) Landsat Archives - Landsat 8 OLI and TIRS, https://www.usgs.gov/centers/eros/science/usgs-eros-archivelandsat-archives-landsat-8-oli-operational-land-imager-and?qtscience_center_objects $=0 \# q t$-science_center_objects/ Viewed June 2019.

NASA (National Aeronautics and Space Administration) Landsat Science, The Worldwide Reference System, https://landsat.gsfc.nasa.gov/the-worldwide-reference-system/ Viewed April 2019.

Advanced Land Observing Satellite, ALOS Research and Application Project of EORC, JAXA, https://www.eorc.jaxa.jp/ALOS/en/about/palsar.htm/ Viewed June 2019.

GEOSPATIAL, Soluciones Espaciales para Infraestructura, ALOS PALSAR, http://www.geospatial.com.co/imagenes-desatelite/alos-palsar.html/

Viewed May 2019.

GLOBAL

WIND

ATLAS,

https://globalwindatlas.info/about/introduction/

Viewed

April 2019. 